\title{
ESTUDO DE ILHA DE CALOR NA CIDADE DE TRÊS LAGOAS (MS)
}

\author{
Andressa Gouveia Ponso ${ }^{1}$
}

\section{Arnaldo Yoso Sakamoto ${ }^{2}$}

\section{RESUMO}

O presente trabalho teve por objetivo analisar a variação da temperatura do ar na cidade de Três Lagoas (MS) a partir de medidas fixas em seis ambientes distintos, indicando a presença de ilhas de calor, e contribuindo para uma discussão dos efeitos e influências causados pela urbanização. A metodologia apoiou-se no Sistema Clima Urbano e desenvolveu-se dentro do sub-sistema Termodinâmico. O episódio analisado refere-se ao dia 11 de janeiro de 2014. Constatou-se com esse episódio que Três Lagoas (MS) apresenta um clima urbano próprio, característico em função da sua organização ocupacional. A ilha de calor teve intensidade de $6,2^{\circ} \mathrm{C}$ e ocorreu no período vespertino, por influencia dos fatores ligados a nebulosidade e ao chuvisqueiro que houve momentos antes. Nesta noite a maior variação entre os pontos de medida foi de 2,3ํㅡ, entre o ponto Rural e Centro.

PALAVRAS-CHAVE: Clima Urbano. Medidas Fixas. Ilha de Calor.

\section{STUDY OF HEAT ISLAND IN THE CITY OF THREE LAKES}

\begin{abstract}
This study aimed to analyze the variation of the air temperature in the city of Três Lagoas (MS) from fixed measures across six distinct environments, indicating the presence of heat islands, and contributing to a discussion of the effects and influences caused by urbanization. The methodology relied on the urban climate system and developed within the sub-system Thermodynamics. The episode analyzed refers to the 11th of January 2014 was found with this episode that Três Lagoas (MS) presents a characteristic depending on their occupational organization own urban climate. The heat island intensity $6,2^{\circ} \mathrm{C}$ and had occurred in the afternoon, by influence of factors related to cloudiness and rain there were moments before. Tonight the greatest variation between the measurement points was $2,3^{\circ} \mathrm{C}$, between Rural and Center Point.

KEY-WORDS: Urban climate. Fixed measures. Heat Island.
\end{abstract}

\footnotetext{
${ }^{1}$ Mestre em Geografia, Universidade Federal de Mato Grosso do Sul (campus de Três Lagoas) andressagponso@gmail.com

${ }^{2}$ Professor Doutor em Geografia, Universidade Federal de Mato Grosso do Sul (campus de Três Lagoas) - arnaldosakamoto@gmail.com
} 


\section{ESTUDIO DE CALOR EN LA ISLA DE LA CIUDAD TRÊS LAGOAS (MS)}

Este estudio tuvo como objetivo analizar la variación de la temperatura del aire en la ciudad de Três Lagoas (MS) de medidas fijas en seis ambientes distintos, lo que indica la presencia de islas de calor, y de contribuir a la discusión de los efectos e influencias causadas por urbanización. La metodología se basa en el sistema de clima urbano y desarrollado dentro del sub-sistema termodinámico. El episodio analizado se refiere al 11 de enero de 2014. Se encontró de este episodio que Três Lagoas (MS) tiene su propio clima urbano, típico en función de su organización profesional. La isla de calor tuvo intensidad $6,2^{\circ} \mathrm{C}$ y se produjo en la tarde, sobre la influencia de los factores relacionados con la nubosidad y chuvisqueiro hubo momentos antes. Esta noche la mayor variación entre los puntos de medición fue $2,3^{\circ} \mathrm{C}$ entre el punto Rural y centro.

PALABRAS CLAVE: clima urbano. Medidas fijas. Isla de Calor.

\section{INTRODUÇÃO}

O presente trabalho refere-se a parte da pesquisa de dissertação realizada no período de 2012 a 2014 pelo Programa de Pós Graduação em Geografia da Universidade Federal de Mato Grosso do Sul, campus de Três Lagoas.

O clima das cidades é parte fundamental no ambiente urbano e seu estudo tem oferecido importantes contribuições à questão ambiental dessas localidades. Um dos objetivos desses estudos é identificar a importância do ambiente edificado, revelando as variações climáticas decorrentes em função das características da estrutura urbana, pois a cidade, em relação às condições atmosféricas, apresenta alterações climáticas diferenciadas das áreas circunvizinhas.

Monteiro (1976) acrescenta que o estudo do clima urbano busca compreender a interação entre o clima (fato natural) e a cidade, ambiente construído, (fato social). Por isso a grande importância em se estudar o clima das cidades, visto que além de despertar o interesse, proporciona compreender as relações existentes entre o uso e ocupação do solo e os sistemas atmosféricos atuantes.

O objetivo desse trabalho foi analisar a variação da temperatura do ar na cidade de Três Lagoas (MS) identificando a presença de ilha de calor na área e 
buscando investigar a relação entre uso e ocupação do solo urbano e o comportamento da temperatura do ar. Os dados analisados para esse trabalho referem-se ao dia 11/1/2014.

Três Lagoas localiza-se no extremo leste do estado de Mato Grosso do Sul, com população de 101.791 habitantes (IBGE, 2010). A hipsometria da área de estudo é caracterizada por ser aplainada, as cotas das curvas de nível variam entre 171 a 403m. A hidrografia da área é bastante rica, banhada pelos rios Sucuriú e Paraná, além dos diversos córregos que cortam a região e as lagoas, característica simbólica da cidade (PONSO, 2014).

Para a realização desta pesquisa, apoiou-se na proposta teórico-metodológica de Monteiro (1976), o chamado "Sistema Clima Urbano" (S.C.U.). Este estudo se desenvolveu dentro do sub-sistema Termodinâmico, abrangendo os níveis de "insumo" (radiação solar e circulação regional da atmosfera), "transformação" (topografia do sítio, uso do solo, estrutura urbana e funções de atividades urbanas) e "produção" (os efeitos causados pelo clima urbano, como o ganho e perda de energia e ilhas de calor).

Foram selecionados seis pontos de medida espalhados pela cidade de Três Lagoas, onde cada um representava um tipo e densidade de ocupação (Figura 1). Os pontos foram assim denominados: ponto 1 (Rural = localizada fora da área urbana, em ambiente de ocupação esparsa com vegetação gramínea); ponto 2 (Lagoa = localizada no interior na cidade em uma área densamente ocupada de caráter residencial e próximo a um corpo hídrico que se localiza dentro da área urbana); ponto 3 (Área central = localizada no centro da cidade com ocupação densa de caráter comercial, com pouca arborização e grande circulação de veículos e pessoas); ponto 4 (Ocupação densa = área de ocupação densa de caráter residencial e comercial e próximo á uma mata pertencente ao Exército que fica próximo ao centro da cidade); ponto 5 (Ocupação esparsa = área de ocupação menos densa de caráter residencial com muitos lotes vazios ao redor e bastante arborização nos quintais das casas e as ruas são na sua maioria de terra); ponto 6 (Conjunto Habitacional = localizado na área periférica a oeste da cidade, com ocupação densa e 
diferenciada por ser do tipo agrupada, as casas são enfileiradas e muito próximas, as ruas são estreitas e asfaltadas e há pouca arborização no local).

Nota-se que a área urbana apresenta uma hierarquia de ocupação de maior densidade para menor densidade no sentido centro-periferia, respectivamente (Figura 1).

Para a escolha dos pontos de media levou-se em consideração setores representativos da área, monitorando-os e buscando a melhor forma de expressar o caráter peculiar da cidade. 


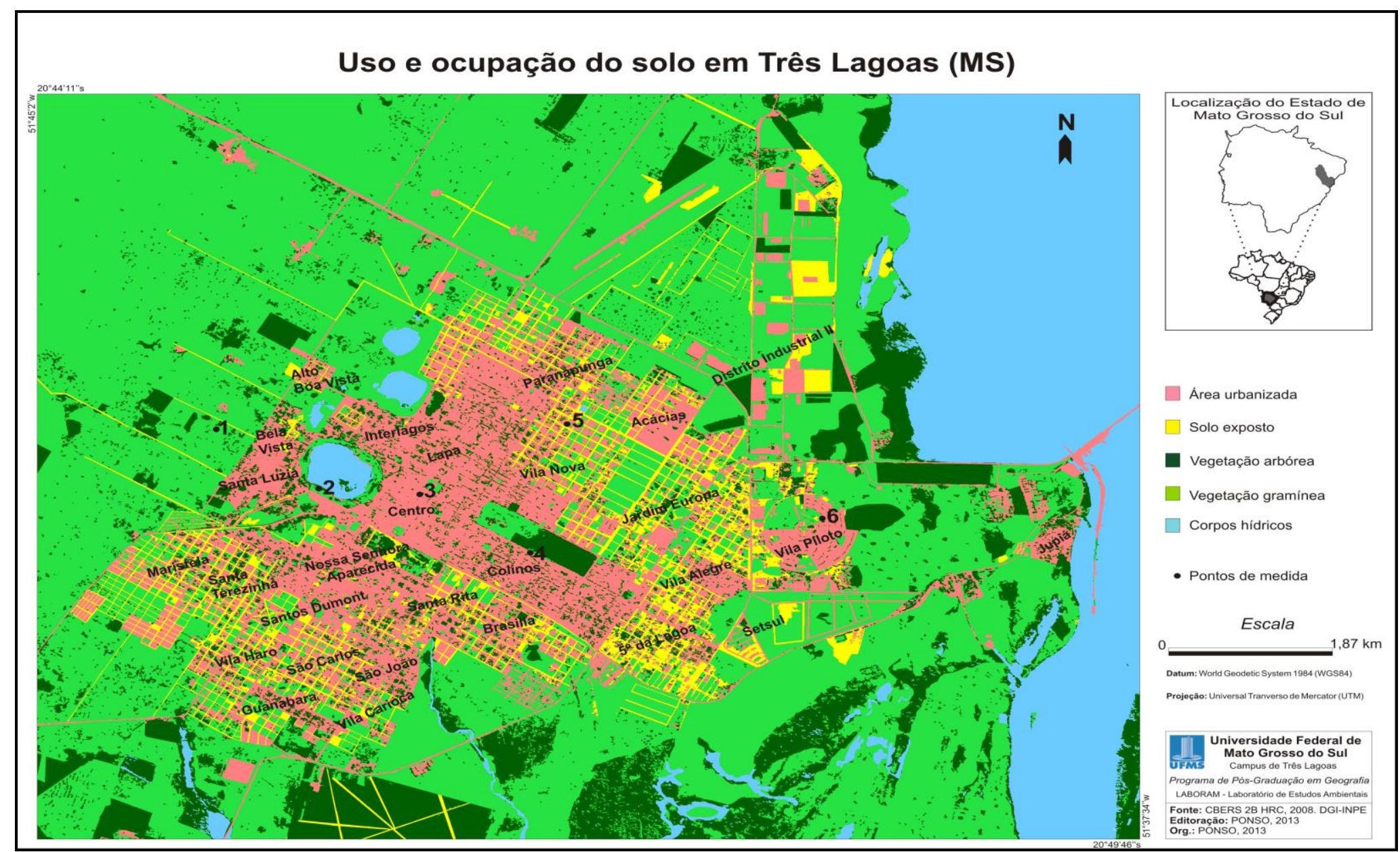

Figura 8: Uso e ocupação do solo em Três Lagoas (MS) com a espacialização dos pontos de medida. 1- Rural; 2- Lagoa; 3- Centro; 4- Ocupação densa; 5- Ocupação esparsa; 6- Conjunto habitacional. 


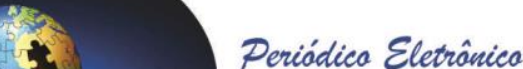

A realização das medidas fixa se deu a partir de sensores de temperatura do ar da marca TINYTAG TALK-2, automáticos, que foram programados para registrar a temperatura média, máxima e mínima de hora em hora.

Os sensores foram colocados dentro de abrigos de madeira, copiados e adaptados do modelo utilizado por Monteiro no estudo feito em Florianópolis no ano de 1987 (SEZERINO \& MONTEIRO, 1990).

Foi realizada também a análise do tempo em escala regional com o objetivo de classificar os sistemas atmosféricos atuantes durante a pesquisa.

\section{DESENVOLVIMENTO}

Durante a realização das análises, no dia 11/1/2014, houve a atuação de um sistema tropical continental (STC) que se caracteriza por altas temperaturas e baixa umidade, este sistema já estava enfraquecido e veio acompanhado por um sistema amazônico (SAM) que se caracteriza por altas temperaturas e umidade, além de elevada nebulosidade (Figura 2).

A temperatura média nesse dia foi de $28,1^{\circ} \mathrm{C}$; a máxima não ultrapassou os $34,4^{\circ} \mathrm{C}$ e a mínima chegou aos $23,8^{\circ} \mathrm{C}$. A UR estava em torno dos $60,8 \%$ e os ventos estavam de $\mathrm{N}$, o que proporcionou um breve chuvisqueiro de $3 \mathrm{~mm}$ na área de estudo, antecedendo o sistema de instabilidades do norte e noroeste (INW) - que proporciona bastante umidade e nebulosidade -, que chegou no dia seguinte na região, proporcionando uma forte chuva de 35,6mm (INMET, 2014). 

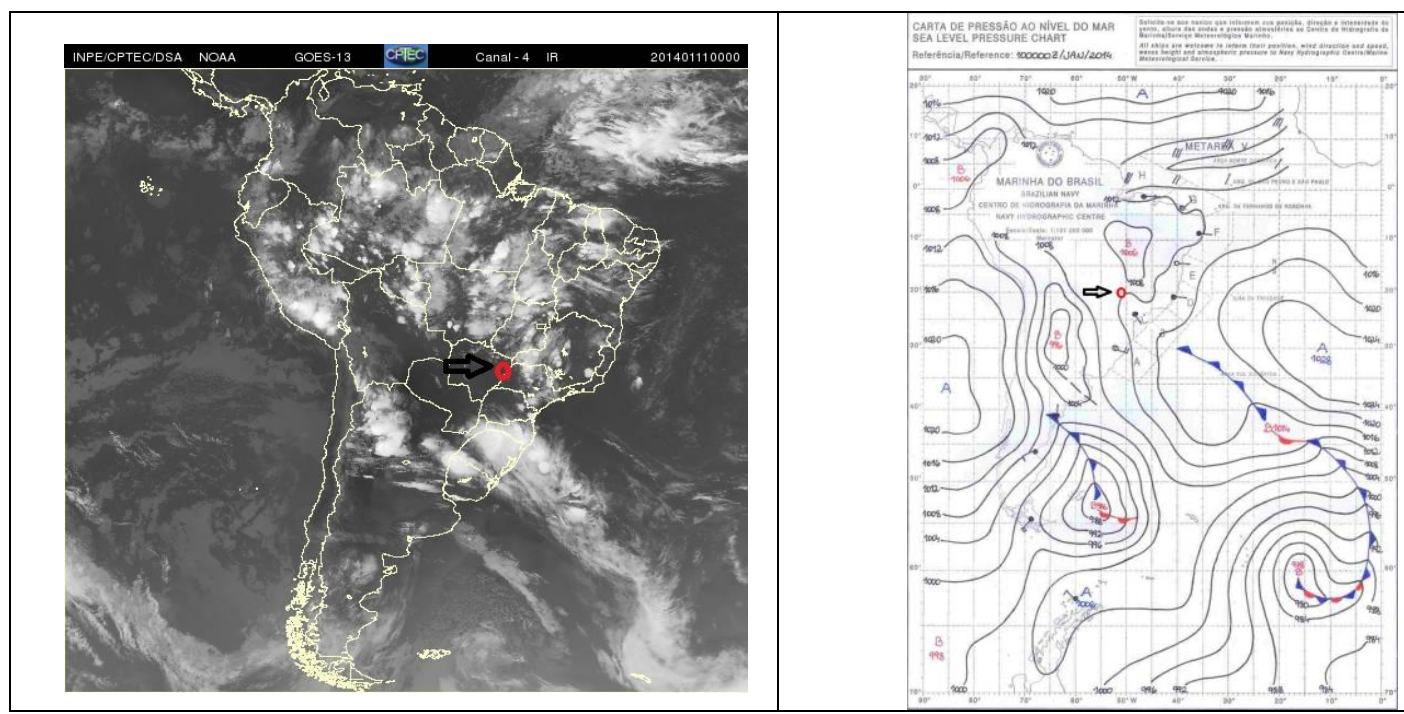

Figura 2 Imagem de satélite meteorológica GOES-12 e carta sinótica da Marinha do Brasil no dia 11/1/2014 às 00Z.

Durante a madrugada do dia 11/1/2014 as temperaturas estavam altas e começaram a se resfriar por volta das $2 \mathrm{~h}$ no ponto Rural, e por volta das $4 \mathrm{~h}$ nos demais pontos (Gráfico 1). O ponto Centro se manteve com as temperaturas mais altas durante toda a madrugada. As mínimas foram registradas às $6 \mathrm{~h}$, havendo uma variação entre os pontos de medida de até $3^{\circ} \mathrm{C}$, o Centro registrando a mínima mais alta $\left(25,2^{\circ} \mathrm{C}\right)$ e o Rural a mais baixa $\left(22,1^{\circ} \mathrm{C}\right)$ (Gráfico 1$)$.

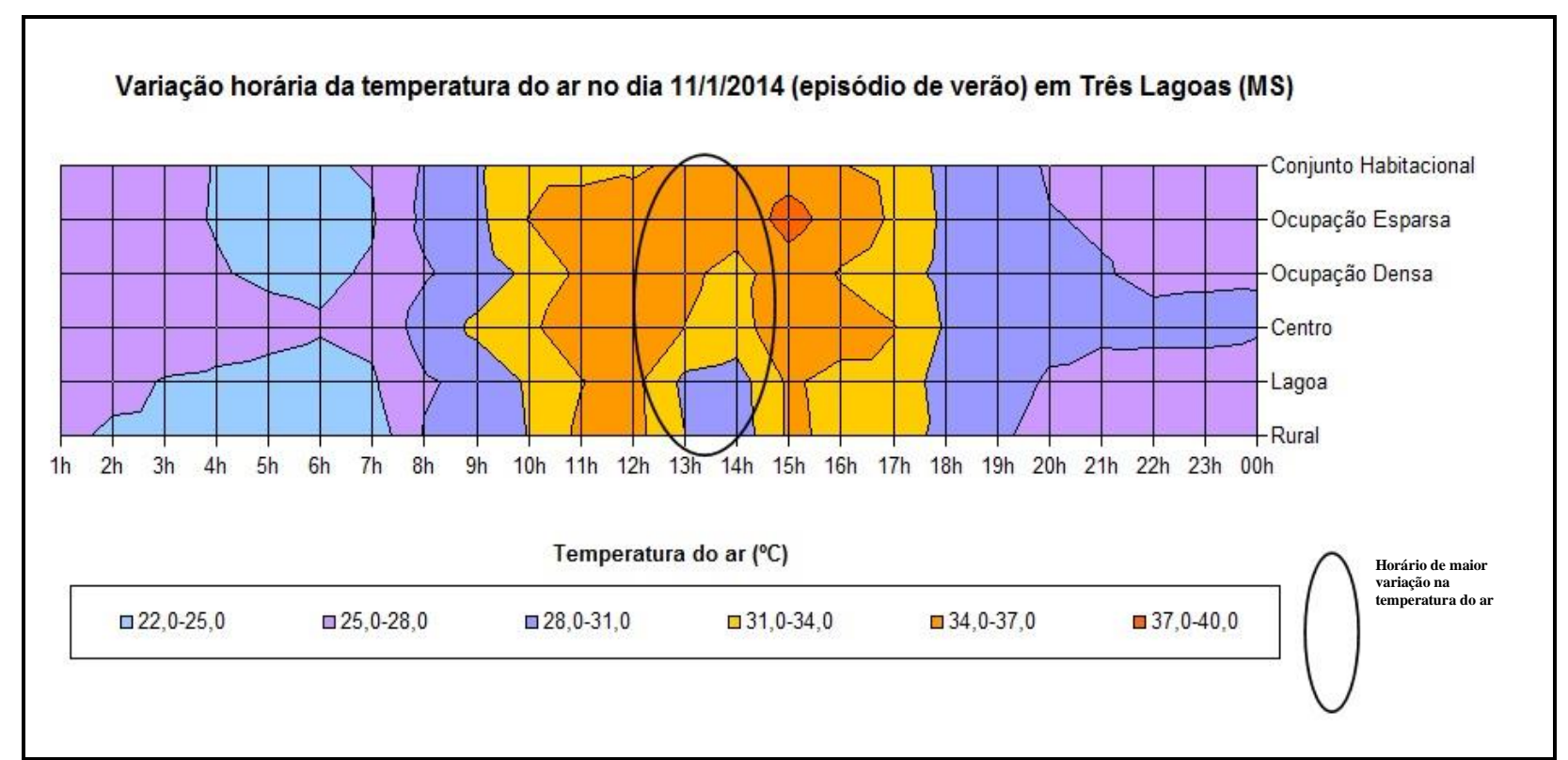

Gráfico 1: Análise temporo-espacial da variação da temperatura do ar entre pontos de medida em Três Lagoas (MS) no dia 11/1/2014. 


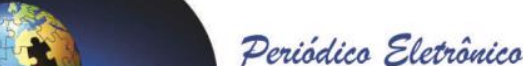

Por volta das $7 \mathrm{~h}$ as temperaturas começaram a subir, gradativamente, em todos os pontos, até às $12 \mathrm{~h}$, quando houve um chuvisqueiro $(3 \mathrm{~mm})$ e as temperaturas baixaram levemente. Entre $12 \mathrm{~h}$ e $13 \mathrm{~h}$ os pontos Rural e Lagoa tiveram uma queda de $4^{\circ} \mathrm{C}$ na temperatura do ar, nos demais pontos essa variação não chegou à $1^{\circ} \mathrm{C}$ (Gráfico 1).

Entre as $14 \mathrm{~h}$ e $15 \mathrm{~h}$ também houve uma mudança brusca, as temperaturas aumentaram até $5,5^{\circ} \mathrm{C}$ no ponto Rural, $4,7^{\circ} \mathrm{C}$ no ponto Lagoa, $4,1^{\circ} \mathrm{C}$ no Centro e nos demais (Ocupação densa, Ocupação esparsa e Conjunto habitacional) não ultrapassaram os 2,8ำ (Gráfico 1).

As temperaturas máximas foram registradas às $15 \mathrm{~h}$, e a temperatura mais alta foi registrada no ponto Ocupação esparsa com $38,1^{\circ} \mathrm{C}$, seguida pelo ponto Centro, com $36,7^{\circ} \mathrm{C}$. Os pontos Ocupação densa e Conjunto habitacional ficaram com temperaturas parecidas, $35,6^{\circ} \mathrm{C}$ e $35,8^{\circ} \mathrm{C}$, respectivamente. O ponto Lagoa apresentou a máxima mais baixa, com $34,4^{\circ} \mathrm{C}$, seguida pelo ponto Rural com $34,6^{\circ} \mathrm{C}$ (Gráfico 1 ).

Após as $16 \mathrm{~h}$ as temperaturas começaram a baixar, levemente, em todos os pontos, e o ponto Centro permaneceu até o fim da noite com a temperatura mais alta que os demais (Gráfico 1).

Nesse dia as maiores variações ocorreram pela manhã e início da tarde, sendo que os horários que apresentaram uma variação mais significativa foram $13 \mathrm{~h}$ e $14 \mathrm{~h}$, com $5,2^{\circ} \mathrm{C}$ e $6,2^{\circ} \mathrm{C}$, respectivamente (Figura 3 ). $\mathrm{O}$ horário das $14 \mathrm{~h}$ foi o pico de maior diferença de temperatura do ar entre os pontos de medida, sendo que o ponto que registrou a maior temperatura foi o Ocupação esparsa, com $35,3^{\circ} \mathrm{C}$, e o ponto com a menor temperatura foi o Rural, com 29,1ํㅡ (Figura 3 e Gráfico 1). 


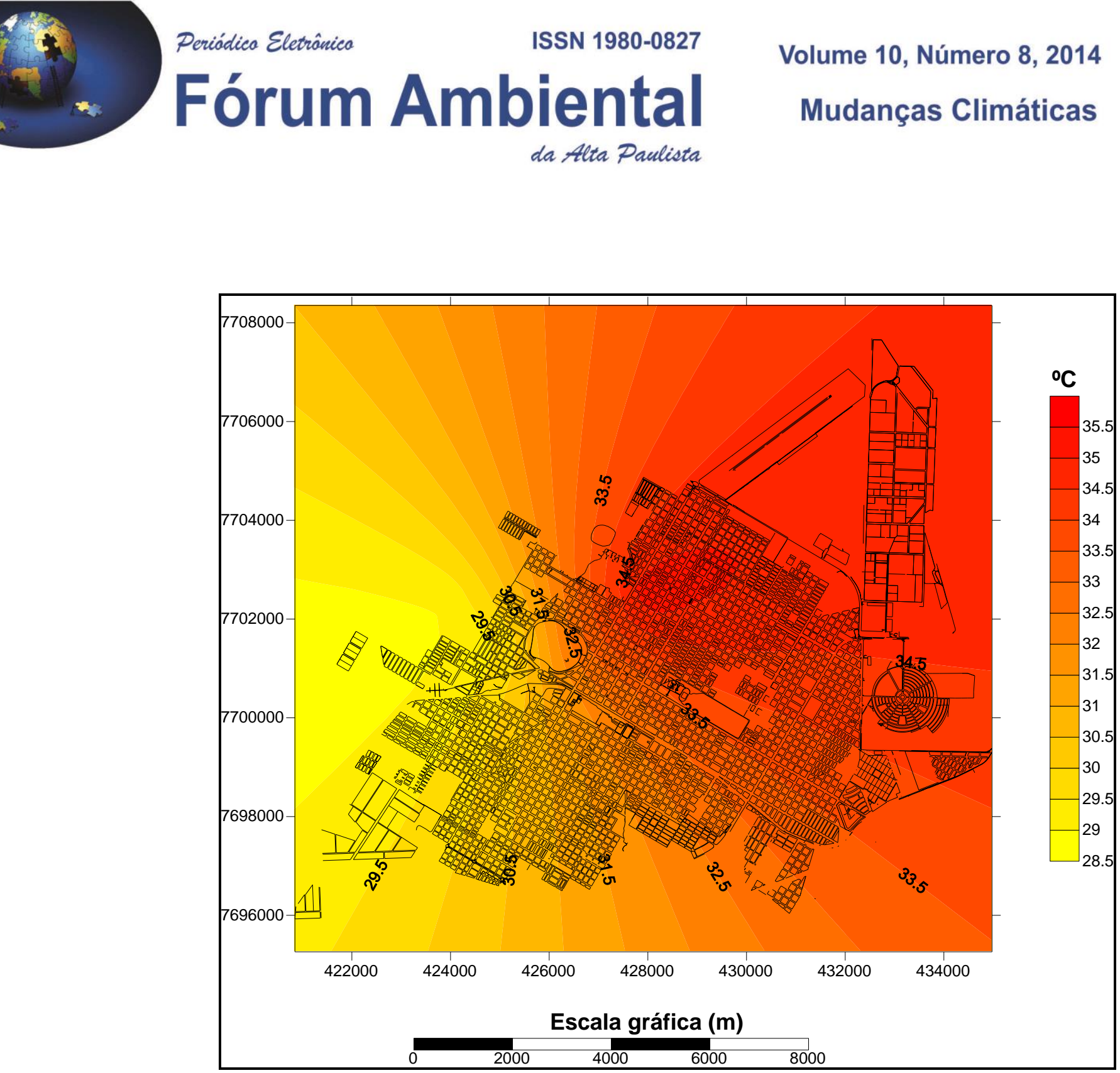

Figura 3: Carta de isoterma do dia 11/1/2014 às 14h em Três Lagoas (MS).

O ponto Ocupação esparsa (Figura 14) causou surpresa por apresentar as maiores temperaturas durante parte do dia (Gráfico 1). Isso se deve ao fato de que havia muita nebulosidade na área de estudo, impedindo que a radiação na superfície fosse direta e intensa em todos os pontos, e a inércia térmica fez com que houvesse a sensação de abafamento. Além disso, esse ponto estava localizado numa área de declividade plana e suave com vertentes voltadas ao $\mathrm{S}$, o que proporcionou as altas temperaturas.

Constatou-se que Três Lagoas (MS) apresenta um clima urbano próprio, característico em função da sua organização ocupacional (Figura 1). Observou-se também que os pontos que apresentaram as maiores temperaturas durante todo o dia 
foi o Centro, seguido pelos pontos Ocupação esparsa e Conjunto habitacional. Esses pontos de medida estavam em localidades densamente ocupadas, com padrões e tipos de materiais de construção diferenciados. O primeiro, de uso comercial, com prédios de até dois andares, com telhados diferenciados, fachadas de metal e/ou vidro, pouca arborização, ruas asfaltadas e muita circulação de veículos e pessoas; o segundo, apesar de ter uma mata próximo, era rodeado por construções comerciais e residenciais, com ruas asfaltas e pouca arborização nas ruas; e o terceiro, é um bairro residencial, mas que apresenta padrões diferenciados do restante da cidade, por ser um conjunto habitacional, o maior existente na cidade, com casas padronizadas uma ao lado da outra, ruas pavimentadas, muito estreitas e em forma de círculo e pouca arborização. Esses fatores são muito propícios para a existência de temperaturas mais elevadas do que no restante da cidade, pois acabam por armazenar e refletir a energia solar, além disso, com esses "obstáculos" não há tanta circulação do vento, o que aumenta ainda mais o armazenamento do calor. Isso acabou por proporcionar a existência de ilhas de calor nessas localidades.

Segundo Lombardo (1985), os materiais de construção provocam a elevação das temperaturas da superfície, causando um aumento da radiação emitida pela cidade, principalmente em situações de calmaria, fazendo com que grande parte da energia irradiada volte às construções urbanas por meio da reemissão radiativa de ondas longas pela atmosfera, provocando as ilhas de calor.

Os demais pontos localizados na área urbana apesar de terem uma ocupação densa ao redor, têm características que acabam por amenizar as altas temperaturas e a existência de variações expressivas.

O ponto Rural obteve as menores temperaturas, tanto em relação ao comportamento diário como no horário das maiores variações. Este ponto estava localizado na área de maior declive dentre todos os pontos, apresentava uma ocupação esparsa, com quase nada de construção, vegetação gramínea por toda a sua volta, o que acaba por absorver a radiação solar, minimizando o intenso calor e consequentemente as altas temperaturas. 


\section{CONCLUSÃO}

Com as análises das medidas de temperatura do ar espalhadas em diferentes pontos da área de estudo, pode-se afirmar que Três Lagoas têm um clima urbano próprio. A começar pelo seu uso e ocupação do solo (Figura 1), apresentando características individuais.

Foi possível observar a influência do uso e ocupação do solo na variação térmica, as diferenças no comportamento diário da temperatura do ar entre os diferentes pontos de medida, a influência da inércia térmica, a influencia dos sistemas atmosféricos atuantes para as variações e diferenças na temperatura do ar entre os ambientes dentro de uma mesma localidade.

A ilha de calor teve intensidade de $6,2^{\circ} \mathrm{C}$ e ocorreu no período vespertino, o que não típico. Nesta noite a maior diferença foi de $2,3^{\circ} \mathrm{C}$, entre os pontos Rural, com a menor temperatura, e o ponto Centro, com a maior; indicando assim, uma ilha de calor de caráter moderado, porém seu pico foi durante tarde, por influencia dos fatores ligados a nebulosidade e ao chuvisqueiro que houve momentos antes.

\section{REFERÊNCIAS}

MONTEIRO, C. A. de F. Teoria e Clima Urbano. São Paulo: IGEOG/USP, 1976.

IBGE - Instituto Brasileiro de Geografia e Estatística. Dados Demográficos 2010. Informações socioeconômicas de Três Lagoas (MS). Disponível em: < http://www.ibge.gov.br/cidadesat/xtras/perfil.php?codmun=500830> Acesso em: 19/06/2013.

PONSO, A. G. Estudo do campo térmico da cidade de Três Lagoas (MS): uma análise sazonal com episódios representativos. Dissertação (Mestrado). Universidade Federal de Mato Grosso do Sul, Três Lagoas, 2014.

SEZERINO, M. L. \& MONTEIRO, C. A. O campo térmico na cidade de Florianópolis: primeiros experimentos. Revista Geosul. Florianópolis-SC: Editora da UFSC, 1990. n. 9, Ano v, Primeiro Semestre, p. 20-60.

INMET. Instituto Nacional de Meteorologia. Dados dos elementos climáticos da estação meteorológica automática de Três Lagoas (MS) no período de janeiro/2014. Disponível em: < http://www.inmet.gov.br/portal/>. 